\title{
Risks of Central Russia Regions Modernization
}

\author{
Evgeniya A. Kogay \\ Tatyana N. Kameneva \\ Kursk State University, Russian Federation; Corresponding Email: eakogay@mail.ru
}

\author{
Doi:10.5901/mjss.2015.v6n6s7p133
}

\begin{abstract}
The article deals with the development of modernization processes in regions of the Central Federal District of Russia in terms of institutional and socio-cultural risks. The territorial disparity on the criteria of modernization in Central Russia is being recorded and the denotation to all six types of modernization is being revealed. The authors consistently view the institutional and socio-cultural modernization risks represented in economic, political, administrative law and social spheres. Special attention is given to the socio-cultural risks of a family which is under the risk because of impossibility to find the balance between advantages and dangers related to the modernization processes and the transformation of family and matrimonial relations.
\end{abstract}

Keywords: Central Federal District, regional dynamics, modernization, risk, social institution, social trust

\section{Introduction}

In recent years the relevance of the research of the dynamics of socio-cultural structures and processes taking place in the Russian regions as well as their analytical presentation in a context of the dynamics of socio-cultural space of all Russia of the post-Soviet period increases. Applying to the methods, indicators and integrated indexes of modernization received in the course of the latest researches (China Modernization Report Outlook, 2010) helps to carry out the analysis of implemented transformations in the Russian regions and to make the integrated assessment of the level of their modernization.

Let us turn to the notion of modernization. Modernization is as a rule connected with the realization of economic and political changes with the implementation of human resources mobilization. Its general function "involves the rise of social and individual capabilities to meet their requirements" (Lapin, 2015, p. 34). The implementation of this function is connected with the establishment of values the centre of which is a person, a human personality. The ensuring of this function efficiency in the Russian regions is connected with the state of economic, social, political and many others institutions and structures which in its turn is considerably determined by the depth of knowledge of the state and dynamics of regional community modernization.

The scientific and sociological analysis of the state of socio-cultural development of the Russian regions shows the presence of considerable territorial disparity. It should be noted that the problem of the territorial disparity of regions is been intensively developed in works of the American researches (Allen, 2002; Tickamyer, 2004; Loba0, 2004). In such a case one of the most important ideas is that it is necessary to take into account the dilemma "equality - efficiency". According to the dilemma, the development of territorial communities can be reached at the ensuring of dynamic balance between the actions of socioeconomic status equalization and the ensuring of social production efficiency at the multiregional level. Following this dilemma contributes to the comprehension of the question of how the tendency of sociocultural development of regions and macroregions of Russia and the Central Federal District in particular respond or do not respond to the challenges of modernization.

\section{Modernization in the Regions of Central Russia}

In the scientific researches on the measurements and analysis of levels and stages of modernization in Russia at large and its regions in particular carried on under the auspices of the RAS Institute of Philosophy CRESC (Centre for Research of Socio-Cultural Change), the indicators and indices of primary, secondary and integrated modernization distinguished according to three spheres of society - economic, social and cognitive (knowledge) - are used (Lapin, 2014). We shall note that the indicators were formulated by Chinese professor He Chuantsy and adopted for the 
estimation of the Russian regions by N.I. Lapin. Applying to them while estimating the modernization processes in Central Russia allows creating the comprehensive view, which depicts the extent of "flexibility" of macroregion development tendencies in all civilizational trends. It should be noted that economically the indicators of modernization under the primary modernization indices (PM) are the Gross Regional Product per life, the number of people engaged in agriculture, the overall number of people in work and the part of added value in service industry towards the GDP; socially these are the part of urban population, the number of physicians per 1000 people, the level of infant mortality and expectation of life; cognitively these are the level of literacy among adults, the number of students going into higher education among population at the ages from 18 to 22. The values of the secondary modernization (SM) are fixed for such spheres as innovations in knowledge, knowledge translation, living standards and economy standards. Here are 16 indicators, their quantities are correlated with their contemporary and yearly checked values in 18-20 rich countries; the calculation of final index and stage phase is conducted. Besides the integrated index of modernization (IM) is used; it includes 12 indicators the majority of which are taken from the methods of two stages measurement. Owing to this index, the measurement of combined level of both modernization stages is carried on.

The estimation of dynamics of Central Russia regions movement on the modernization scale since 2000 to 2012 according to the calculations made by the ISEDT RAS (Vologda) on the basis of information system "Modernization" clearly shows that there is a territorial disparity by modernization criteria in this federal district. As of 2012 we discover the regions of all six modernization types: we see here both the regions at the initial stage of primary (industrial) modernization (type 1) and the regions which have reached high - even under the world measurements - stage of secondary modernization (type 6). The sixth and the highest type of modernization includes Moscow, the capital of Russia, and Moscow region; the fifth type - Kaluga and Yaroslavl regions, the forth type - Ivanovo region, the third type Vladimir, Voronezh, Kursk, Tver and Tula regions, the second type - Belgorod, Bryansk, Kostroma, Lipetsk, Oryol, Ryazan and Smolensk regions, the first type - the lowest one - includes Tambov region. Thus it should be noted the disparateness of the modernization of different regions of the district, as well as unbalance of the regions modernization processes. In such a case it should be realized that the further prolongation of current rates and structure of modernization dynamics will lead to its stagnation, and then to the recession in the majority of regions of Central Russian.

\section{Institutional Risks of Modernization}

In this macroregion both the problems connected with the realization of modernization transformations (here we cannot but remember famous sociologists A. Giddens and U. Beck who point out that we have to do with the society transition to the stage of reflexive modernization accompanied by the social relations exclusion out of local context and their inclusion to global one) and the problems of facing obstacles appearing in the way of modernization processes implementation are fixed. According to Giddens (1994, p. 56) "... inconceivable and increasing interdependence of daily decisions and global consequences is a key element of a new agenda". It should be noted that the introduction of a notion "a sphere of risk" belongs to Giddens (1990, p. 102) and at the same time the researcher points out three components of this sphere: threats and dangers produced by the reflexivity of modernity; the threaten of violence over a person is connected with wars industrialization and, finally, the threaten of feeling of aimlessness formation and meaninglessness of human existence caused by human attempts to compare his or her own being to the reflexive modernization.

At the same time we should agree with Beck (1992) who points out that the risks production becomes the important factor of the society social structure change dividing it into those who produces risks and those who consumes them. Indeed these risks backfire to their producers in course of time...

Daily decisions of regional life are as a rule connected with the work of social institutions. Thus we can speak about institutional problems, obstacles as well as modernization risks - institutional and socio-cultural. It bears reminding that the most important function of institutions is a rise of certainty in territorial entities (the Central Black Earth regions) behavior and the reduction of risk level since a risk being an objective phenomenon is an indispensable feature of any economic entity. In order to find out the essence of the institutional risk it is necessary to turn to the notions of a social institution and "institutional".

The social institution is understood as a form of organization of social life, which provides stability of connections and relations among social entities. It can also be considered as a mechanism that provides the particular number of constantly repeating and reproducing social relations and social practices. Consequently, the notion "institutional" should be connected with the social mechanisms of impact on socio-economic and socio-cultural relations, these mechanisms are applied for structuring these relations and placing them under the specific vector of development. In such a case, the institutional risk points out the inefficiency of the above-noted mechanisms, the irrationality of acting social institutions and the imperfection of institutional sphere on the whole. 
An institutional risk can be defined as "a possibility of undesired event occurrence caused by the irrationality of institutions, the imperfection of institutional sphere and the opportunistic behavior of economic entities" (Grozova \& Tsvetkova, 2012, p. 54). Institutional risks can be nominally divided into four groups: risks operating in a political, economic, administrative law and social spheres. Let us consider their manifestation in the regions of Central Russia in the context of modernization processes realization in a more detailed way.

The political factors of the institutional risks are expressed in such demonstrations of political institutions instability as limitations of possibilities of political choice, authoritarian methods of governance, restricting free speech and will expression. The rise of risk of management crisis, the growth of detachment of authorities and civil society should be placed among them. Thus, the expert opinion poll carried on by the researchers from Voronezh in 2012 within the framework of the project "Modernization Potential of Voronezh region: the experience of research and realization conditions" has determined that the political elite of the region have specific modernization potential at the government agencies level, besides it is characterized by sluggishness, social selfishness and snobbery (Glukhova, 2014, p. 70). The socio-cultural measurement of modernization processes in Voronezh region has confirmed an important theoretical thesis that the economic growth is directly connected with socio-cultural shifts in consciousness of inhabitants of the region, it increases the request for post-material values among which it is possible to note the readiness to participate actively in public life. However, the realization of the possibility of civil activity manifestation meets all-round difficulties.

The Belgorod sociologists focus their attention on the fact that today the regional policy is focused, first of all, on the achievement of results measured in "physical" indicators. In this region there is established the low level of public initiative, the dependency position of citizens who expect "that the authorities must settle everything for them, there is an absence of citizens' desire to participate in any form of local questions solution" (Ovchinnikov, 2014). The political instability in Oryol region, as experts believe, turns into the prolongation of finding of area in a group of strategic lag regions.

Besides, it should be noted that the mistrust of inhabitants of Russian regions to social institutions is constantly increasing - first of all to such institutions as regional representatives of political parties, police, regional parliament and mass media (Kogai et al., 2015).

Bringing up the question of institutional trust in regions of Central Russia it is necessary to address the reconstruction of the Russian social trust space carried out by the Fund of Public Opinion (FPO) according to two national mega polls of "Georeyting" of 2007 and 2008. The description of the Russian social trust space affected 68 regions. Its structure was presented by three axes: the first axis is institutional (public) trust, the second axis is personal responsibility at a remote and average social distance and the third axis is personal civil activity. The reconstruction has showed five clusters of the Russian regions: 1) a "civil" cluster (19 regions) - public trust at the existence of both personal responsibility and personal civil activity; 2) a "paternalistic" cluster (9 regions) - public trust in the absence of personal responsibility; 3) an "activist" cluster (11 regions) - personal civil activity in the absence of public trust; 4) an "individualist" cluster (11 regions) - personal responsibility in the absence of public trust and personal civil activity and finally 5) a "social and depressive" cluster (18 regions) - the absence of trust, responsibility and activity (Petrenko, 2009).

In this research all the entities of Central Russia were presented which allows classifying these regions on the relevant groups. It should be noted that none of the entities of the CFD has got into the "paternalistic" cluster (see table 1). This fact has become an important confirmation that in Central Russia as well as in Russia in general the new type of an individual which depends on power and other social institutions less and more often counts on itself is gradually being established.

Table 1. The Typology of the CFD Entities in a Space of Social Trust

\begin{tabular}{llll}
\hline "Civil" cluster & "Activist" cluster & "Individualist" cluster & "Social and depressive" cluster \\
\hline Belgorod region & Kaluga region & Bryansk region & Vladimir region \\
Ivanovo region & Moscow & Kostroma region & Voronezh region \\
Oryol region & Moscow region & Kursk region & Lipetsk region \\
Smolensk region & & Tambov region & Ryazan region \\
Yaroslavl region & & Tula region & Tver region \\
\hline
\end{tabular}

We see that the minimum number of regions is in the "activist" cluster, thus ten regions have got into the clusters characterized by the absence of public trust. The research shows that the features of civil climate in Central Russia as well as in Russia in general are set substantially not only by geographical position or economic development, but sociocultural environment, which determines the nature of interpersonal and social trust-based relationships. Thus, the 
indicators of social trust of the population show the strengthening of tension of social space that complicates the stable development of territorial communities. It must be noted that the above-mentioned institutional risks caused by the political factors are not purely specific for the CFD regions; nevertheless, their intensity constrains the implementation of modernization processes.

The economic factors of institutional risk have a significant influence on the assessment of investment attractiveness and the assessment of business favour in this or that region. The assessment of risk showing the probability of investments and their income loss is an important indicator of investment potential of a region. An investment risk is a risk of capital investments depreciation owing to actions of government authorities. The integrated assessment of the investment risk includes such risks as legislative, economic, financial, criminal, ecological and administrative. It is obviously important to address the question of integrated risk dynamics in the CFD fixed by the independent rating agency RAEX ("Expert RA"). Thus in 2014 Lipetsk (the 2nd place in the Russian Federation) and Voronezh (the 3rd place in the Russian Federation) regions became obvious leaders; Moscow, Tambov, Belgorod and Kursk regions had a slim margin. Moscow closed the list of ten regions with the minimum risk. Thus Ivanovo (the 57th place in the Russian Federation) and Kostroma (the 59th place in the Russian Federation) regions showed obvious lag according to this indicator in comparison with the other regions of Central Russia, and Ivanovo region performed obvious strengthening of investment risk in dynamics.

High tax burden and considerable expenses connected with the passing of administrative procedures and unreliability of financial guarantees system for enterprises slow down the development of the business environment in regions. Against a background of the small and medium enterprise full support declaration businessmen have hard times; - they have to act in constantly changing conditions, in the conditions of continuous increase of the uncertainty factor rather than of its decrease.

Administrative law factors, as a rule, are the most formalized. These factors are connected with the distortions and defects of administrative facilities structures, the deformation of regulating influence, the constant variability and opacity of the legislation as well as the low level of legal and information environment of business (Grozovan \& Tsvetkova, 2012). The above-mentioned factors find their reflections in the respondents' answers got during the sociological polls within the implementation of the All-Russian research program "Socio-cultural Evolution of Russia Regions". Thus, according to the sociological survey conducted in 2012 in Kursk region on the basis of a standard technique "Socio-cultural portrait of a region" answering the question "How safe do you feel yourself today from various dangers?" the respondents pointed out first of all crime (60\% of answers), then poverty $(58,5 \%)$, officials arbitrary rule $(56,5 \%)$, ecological threat $(50,7 \%)$ and the danger of law-enforcement agencies arbitrariness (49,6\%). We see that the risks being transformed into the dangers of administrative law character are the ones of the top five significant risks in the region. It should be noted that in the majority of other Russian regions where the similar researches are being conducted the inhabitants also point these risks out.

As a rule, the irrationality of social institutions functioning forms the basis of the social risks, which has the aggravation of social situation and the deformation of public structure as a consequence. These risks raise the instability of people's life, are shown in growing discontent in social moods and are also fixed in distortions of habitual standards of behavior. Among the risk factors of the macroregion social sphere it is necessary to point out the insufficiency of social welfare (especially concerning people with disabilities), the degradation of education quality, the irrationality of labor market regulation as well as the insufficient adjustability of demographic processes that turns out as the decrease of macroregion population.

\section{Socio-cultural Risks of Modernization and Family Relations}

It is necessary to note that the modernization processes are connected with the considerable socio-cultural risks (Stacey, 1993, p. 545; Nye, 2012). The manifestation of such risks can be considered on the example of such social institution as a family. It should be noted that many researchers absolutely fairly write about destructive effect of modernization processes on the social sphere development. As Keler (2002, p. 30) states "even at its early stages modernity had been irrevocably destroying the world of household as the center of traditional forms in social sphere. Two centuries later... it is destroying the world of formal organizations and remaking the world form into the extremely unstable environment of constantly variable networks". Under the influence of social reforms, which are followed by the "reduction" of risks to the social environment of Russia "this environment consisting of masses of fragile micro worlds of interpersonal communities, identifications and socialites connected by the web of weak interactions has collapsed under the pressure of these processes," Yanitskiy (2003, p. 30) writes. The atomized environment from the absorber of risks has turned into their producer. The social environment of the Russian society, O.N. Yanitskiy believes, possesses an essential counter- 
modernization potential and very often it serves as an obstacle to the modernization processes of the country.

Post-industrialism and globalization place at risk the developing for centuries institution of marriage and family first of all by atomizing and destroying the traditional model of a family which is understood as a registered marriage in which 2 or 3 children are born and brought up, and the head of a family is a man who provides the family and makes the most important decisions. According to the majority of the respondents (Kursk region, 2013, $\mathrm{N}=560$ among the population at the age over 16 years old) the process of the society global transformation has generally effected socio-cultural (43\%), labor (41\%) and educational (39\%) spheres of activity. Nevertheless, though the family is still occupying one of the leading positions in the system of terminal values, it is actually endangered by the transforming society.

Thereby we are discussing high dangers and risks to which one of the major social institutions - the institution of a family - is exposed. Thus, it is possible to assume that first of all the "factors of risk" influencing the stability of institution of a family and corresponding family and marriage practices include the expectation of these dangers. The respondents' answers allow saying that both the opinions concerning the risk situation and the degree of its awareness have a significant importance in the process of decision-making in the family and matrimonial sphere. On the one hand the risk as a rise of uncertainty and destruction of event objectivation - performs the destructive and destabilizing function. But on the other hand it can be presented as the mean of human resources mobilization and the mean of their activity and creative abilities development. Thereby the generations of people who grew up in the conditions of risk include them into the social practices.

The results of the sociological research conducted in Kursk region show that the majority of the respondents consider the modern society to put the family and matrimonial relations at risk (72\%). The inhabitants of the region voice concerns for the future of families and consider that the family and matrimonial relations in the modern society are subjected to the constant risks and are in danger. In most cases, the respondents negatively estimate the safety of their own families. More than a half of the respondents being married for the second time consider their families not to be protected from the modern life shocks, about the same number of people being in a common-law marriage note that their families are at a risk rather than in safety. The positive assessment of the level of social protection of a family in the modern society was given generally by the respondents who have never been married $(22,3 \%)$ or are in a common-law marriage $(22,6 \%)$. Thereby as for this social institution it is possible to draw a conclusion that a family gets to the sphere of risk first of all owing to the impossibility to find the balance between advantages and dangers connected with the postindustrialism modernization processes and the family and matrimonial relations transformation.

\section{Conclusion}

The prospect of stagnation and recession of modernization in Central Russia regions strengthened by various risks cannot be considered acceptable. Overcoming this tendency demands the development of a purposeful strategy providing the rise of economic, social and cognitive and innovative indicators of regions. The formation of such a strategy, no doubt, has to rely on knowledge of modernization processes features of each region of the CFD. We believe that the modernization challenges which the Russian regions are facing today are also aimed at the implementation of institutional transformations capable to lead not to the elimination but to the noticeable decrease of modernization risks intensity.

\section{Acknowledgment}

The article was prepared with the support of the Russian Humanitarian Science Foundation within the framework of the project "The Socio-cultural Potential of Modernization Transformations of the Central Black Earth Regions" (No. 15-0300506).

\section{References}

Allen, B. L. (2002). Race and Gender inequality in Homeownership: Does Place Make a Difference? Rural Sociology, № 4, 603-621.

Beck U., Giddens A., Lash S (1994). Living in a Post-Traditional Society. Reflexive Modernization. Politics, Tradition and Aesthetics in the Modern Social Order. Stanford, CA : Stanford University Press, 56-109.

Beck, U. (1992). Risk Society. Toward a New Modernity. L.: SAGE.

China Modernization Report Outlook: 2001 - 2010. (2010). Peking University Press.

Giddens, A. (1990). The Consequences of Modernity. Cambridge: Polity.

Glukhova, A. V. (2008). The Modernization Project: Long-Term Strategy, or Lost Opportunity? (on the Basis of Voronezh Case Study). The Bulletin of Voronezh State University. The Series: History. Political Science. Sociology, 4, 68-73. [in Russian]

Grozova, O. S., \& Tsvetkova, G. S. (2012). The Nature and Factors of Institutional Risk The Bulletin of South Ural State University. The 
Series: Economy and Management. Edition, 22 (2810), 54-59. [in Russian]

Keler, J. (2002). The Modernization: Humanization of Society, or Corrosion of Social Being? (Critical Notes on Modernization Theory). Sociological Studies, 7, 23-32. [in Russian]

Kogay, E. A., Pasovets, Y. M., Kogai, A. A., Yatskova, D. S. (2015). Kursk Region on the Socio-cultural Map of Russia: Monograph. Kursk: Municipal Unitary Enterprise "Kursk Municipal Printing Office" [in Russian]

Lapin, N. I. (2014). The Problems of Conception Formation and Human Measurements of Gradual Modernization of Russia and Its Regions Strategy. Sociological Studies, 7, 8-19. [in Russian]

Lapin, N. I. (2015). Modernization as a Global Challenge and the Strategies of Its Socio-cultural Efficiency Increase in Russian Regions. Regional Sociology: the Problems of Russian Social Space Consolidation. Moscow: New Chronograph, 34-63. [in Russian]

Lobao, L. (2004). Continuity and Change in Place Stratification: Spatial Inequality and Middle-Range Terrinorial Units. Rual Sociology, 69, 1-30.

Nye, F. I., L. N. W. Hoffman (2012) The Employed Mother in America. New York : Literary Licensing, LLC.

Ovchinnikov, V. (2015). Annual Report on the State of Civil Society of Belgorod Region in 2014. [Online] Available: http://op31.ru/910/ (June 15, 2015).

Petrenko, E. S. (2008). The Civil Society: the Mapping of Russian Regions on the Basis of the Public Opinion Foundation Polls 20072008. NOVAINFO.RU. Economic and Scientific and Technical Online Magazine. [Online]. Available: http://st3.novainfo.rul grazhdanskoe-obshchestvo-kartografiya-rossiyskih-regionov-po-rezultatam-oprosov-fom-2007-2008-gg (December 15, 2012).

Stacey, J. (1993) Good Riddance to "The Family": A Response to David Popenoe. Journal of Marriage and Family, N 55, Aug., 545-547.

Tickamyer, A. R. (2000). Space matters! Spatial inequality in future sociology. Contemporary Sociology. Washington, Vol. 29. Issue 6, 805-813.

Yanitsky, O. N. (2003). The Sociology of Risk: Key Ideas. The World of Russia, 1, 3-35. [in Russian] 